\title{
Fatty acids, lipid mediators, and T-cell function
}

\section{Anja J. de Jong, Margreet Kloppenburg, René E. M. Toes and Andreea loan-Facsinay*}

Department of Rheumatology, Leiden University Medical Centre, Leiden, Netherlands

\section{Edited by:}

Oreste Gualillo, Santiago University Clinical Hospital, Spain

\section{Reviewed by:}

Giamila Fantuzzi, University of Illinois at Chicago, USA

Fulvio D'Acquisto, Queen Mary

University of London, UK

${ }^{*}$ Correspondence:

Andreea loan-Facsinay, Department of Rheumatology, Leiden University Medical Centre, Albinusdreef 2, 2333

ZA, Leiden, Netherlands

e-mail:a.ioan@lumc.nl
Research toward the mechanisms underlying obesity-linked complications has intensified during the last years. As a consequence, it has become clear that metabolism and immunity are intimately linked. Free fatty acids and other lipids acquired in excess by current feeding patterns have been proposed to mediate this link due to their immune modulatory capacity. The functional differences between saturated and unsaturated fatty acids, in combination with their dietary intake are believed to modulate the outcome of immune responses. Moreover, unsaturated fatty acids can be oxidized in a tightly regulated and specific manner to generate either potent pro-inflammatory or pro-resolving lipid mediators. These oxidative derivatives of fatty acids have received detailed attention during the last years, as they have proven to have strong immune modulatory capacity, even in pM ranges. Both fatty acids and oxidized fatty acids have been studied especially in relation to macrophage and T-cells functions. In this review, we propose to focus on the effect of fatty acids and their oxidative derivatives on T-cells, as it is an active area of research during the past 5 years. The effect of fatty acids and their derivatives on activation and proliferation of T-cells, as well as the delicate balance between stimulation and lipotoxicity will be discussed. Moreover, the receptors involved in the interaction between free fatty acids and their derivatives with T-cells will be summarized. Finally, the mechanisms involved in modulation of T-cells by fatty acids will be addressed, including cellular signaling and metabolism of T-cells. The in vitro results will be placed in context of in vivo studies both in humans and mice. In this review, we summarize the latest findings on the immune modulatory function of lipids on T-cells and will point out novel directions for future research.

Keywords: T-cells, fatty acids, lipid mediators, obesity, inflammation

\section{INTRODUCTION}

Obesity is increasing in the Western society, and obesity-linked complications are under intense scrutiny. Among these, not only metabolic disorders, such as diabetes mellitus and dyslipidemia, but also cardiovascular disorders, such as hypertension and ischemic heart diseases, have been shown to be associated with obesity $(1,2)$. More recently, also chronic diseases in which inflammation plays a role such as osteoarthritis, rheumatoid arthritis, inflammatory bowel disease, chronic obstructive pulmonary disease, and asthma have been associated with obesity (3-6). Likewise, evidence exists indicating a relationship between obesity and increased susceptibility for infections (7), as well as a lower response to vaccination (8) indicating that obesity can impact immune responses. Although the mechanisms underlying these associations are unclear, adipose tissue-derived inflammation could play a role in the development and progression of these diseases. Indeed, adipose tissue serves not only as an energy depot but it is also a highly active metabolic and endocrine organ, affecting whole body metabolism $(3,9,10)$.

The adipose tissue consists of adipocytes and the stromal vascular fraction, in which a variety of immune cells can be found. Among these, macrophages and T-cells are the most abundant (11). Expansion of the adipose tissue is accompanied by an increased infiltration of immune cells with a pro-inflammatory phenotype. The cross-talk between the infiltrating cells and the tissue-resident adipocytes leads to secretion of adipokines, cytokines, chemokines, and lipids with a predominant proinflammatory character $(3,10)$. Moreover, the levels of various adipokines and cytokines are altered in obese individuals compared to lean ones (e.g., leptin, adiponectin, IL-6) (12).

This cross-talk has also been shown to affect the function of adipocytes, such as lipolysis, which will most likely result in an altered concentration of circulating free fatty acids. Indeed, obese persons have higher levels of free fatty acids in plasma compared to lean persons (13-15). Whether and which of these soluble factors (adipokines, cytokines, lipids, etc.) contribute to obesity-mediated inflammatory effects in diseases is still under investigation.

Several indirect lines of evidence suggest that fatty acids can modulate the immune response. One of these is that levels of several fatty acids are associated with levels of inflammatory markers in healthy individuals (16). More directly, the type of fatty acids contained in the diet has been suggested to influence the risk of development of inflammatory diseases in which the immune system plays an important role. Fatty acids from animal sources, such as meat and poultry, are mainly saturated fatty acids or omega- 6 $(\omega 6)$ unsaturated fatty acids, while fatty acids derived from plantbased foods, oils, and certain types of fatty fish consist mainly of $\omega 3$ unsaturated fatty acids. Diets rich in $\omega 6$ polyunsaturated fatty acids (PUFAs) increase the risk of development of inflammatory diseases, such as rheumatoid arthritis, inflammatory bowel 
disease, and asthma (17). On the other hand, diets rich in $\omega 3$ PUFAs seem to have anti-inflammatory effects as indicated both by the decreased risk and the amelioration of these diseases (1720). Moreover, it has been shown that after in vivo challenge with a pathogen, the host survival and pathogen clearance is affected by diets enriched in fatty acids, although this is dependent on the infectious agent and the fatty acids used $(21,22)$.

Additionally, unsaturated fatty acids can be oxidized to generate either potent pro-inflammatory or pro-resolving lipid mediators. These lipid mediators have strong immune modulatory capacity and are generated in a timely and controlled manner during an inflammatory response (23). Pro-inflammatory lipid mediators, such as prostaglandins and leukotrienes, are produced first. When the tissue-damaging or infectious agent is removed, the production of pro-resolving lipid mediators associates with restoration of normal tissue homeostasis (24).

In conclusion, several publications indicate that fatty acids and lipid mediators derived from fatty acids can potently influence the immune system. Although it is often unclear which cells are responsible for the immune modulatory effects of fatty acids, these lipids have been shown to affect the function of several immune cells, especially antigen-presenting cells and T-cells $(25,26)$. In this review, we propose to summarize the knowledge regarding the effect of fatty acids and their oxidative derivatives on T-cells, both in vitro and in vivo, as it has been an active area of research during recent years.

\section{FATTY ACIDS}

Fatty acids serve not only as fuel for cells but are also components of cell membrane phospholipids and glycolipids, and precursors of bioactive lipid mediators (27). Fatty acids are hydrocarbon structures, which can differ in the number of carbon atoms and the degree of saturation. Therefore, they are classified according to length (number of carbon residues in the lipid backbone), saturation, and number and position of the double bonds. Fatty acids can be either short-chain (4-10 carbons), medium-chain (12-14 carbons), long-chain (16-18 carbons) or very long-chain fatty acids ( 20 or more carbons). In addition, these lipids can be classified according to the presence or absence of a double bond in the backbone. Fatty acids that do not have a double bond are called saturated fatty acids and those having one or more double bonds are called monounsaturated fatty acids (MUFAs) or PUFAs, respectively. The position of the double bond determines whether PUFAs can be characterized as $\omega 3, \omega 6$, or $\omega 9$, whereby $\omega$ indicates the methyl end of the fatty acid and the number indicates the carbon counted from the methyl end that contains a double bond. Table 1 shows an overview of fatty acids most commonly used in literature. Some of the PUFAs, especially AA, DHA, and EPA and their influence on the immune system have been extensively reviewed elsewhere $(27,28)$, therefore, they will be excluded from the present review.

\section{EFFECT OF FATTY ACIDS ON T-CELLS}

Several studies have focused on the effect of fatty acids on T-cells. Although these studies differ in experimental setting, especially regarding the concentration of the fatty used, the type of T-cell studied, and the T-cell stimulus, the overall data suggest that low
Table 1 | Examples of saturated, monounsaturated, and polyunsaturated fatty acids that are most commonly used in literature.

\begin{tabular}{lll}
\hline Type & Isomer & Name \\
\hline Saturated & $4: 0$ & Butyric acid \\
& $12: 0$ & Lauric acid \\
& $14: 0$ & Myristic acid \\
& $16: 0$ & Palmitic acid (PA) \\
& $18: 0$ & Stearic acid (SA) \\
Monounsaturated & $18: 1(\omega 9)$ & Oleic acid (OA) \\
Polyunsaturated & $18: 2(\omega 6)$ & Linoleic acid (LA) \\
& $18: 3(\omega 3)$ & Alpha-linolenic acid (ALA) \\
$18: 3(\omega 6)$ & Gamma-linolenic acid (GLA) \\
& $20: 4(\omega 6)$ & Arachidonic acid (AA) \\
$20: 5(\omega 3)$ & Eicosapentaenoic acid (EPA) \\
$22: 5(\omega 3)$ & Docosapentaenoic acid (DPA) \\
$22: 6(\omega 3)$ & Docosahexaenoic acid (DHA) \\
\hline
\end{tabular}

concentrations of fatty acids can influence the proliferation of T-cells, whereas higher concentrations induce apoptosis in a dosedependent manner, through the induction of several pathways (29-34). In addition, the concentration at which apoptosis occurs is also determined by the degree of saturation and the length of the fatty acid. While short-chain fatty acids (SCFA) are not toxic even at a concentration of $800 \mu \mathrm{M}$ or higher (30), longer, and more unsaturated fatty acids can already be toxic in low concentrations [e.g., linoleic acid (LA)] is toxic at $100 \mu \mathrm{M}(30-32)$.

In contrast to the apoptotic effects, the modulatory effects of low, non-toxic concentrations of fatty acids on proliferation do not seem to correlate with length of the fatty acids tested. There are only a few studies studying the proliferation of T-cells after incubation with fatty acids and they use different stimuli $(29,33$, 35). While proliferation of anti-CD3/anti-CD4 stimulated T-cells was not influenced by palmitic acid (PA) (29), concanavalin A (ConA) stimulated T-cells proliferated less in the presence of PA (33), indicating that fatty acids can have different effects depending on the stimulus used for T-cell activation. This is supported by the fact that while proliferation of T-cells stimulated with ConA was differentially affected by the saturated fatty acids stearic acid (SA), and the unsaturated fatty acids oleic acid (OA) and LA (33), stimulation with anti-CD3/anti-CD28 led to increased proliferation with all tested fatty acids [e.g., LA, SA, $\gamma$-linoleic acid (GLA), $\mathrm{PA}, \mathrm{OA}$, and palmitoleic acid] independently of saturation degree (35). Overall, the data indicate that different fatty acids can modulate proliferation of T-cells, although this is likely dependent on the stimuli used.

Only a handful of studies have investigated cytokine production by T-cells treated with fatty acids and they generally indicate that fatty acids can modulate secretion of several cytokines, such as TNF $\alpha$, IL-6, IL8, IL1 $\beta$, IL-2, IL10, and IFN $\gamma$ (36-38). This modulation has been shown primarily for unsaturated fatty acids such as OA and LA using T-cells activated by a polyclonal stimulus, such as ionomycin (38) or ConA (37). The effect of saturated fatty acids on cytokine secretion by activated T-cells is unclear. However, saturated fatty acids induced cytokine secretion in T-cells in 
the absence of T-cell activation in a dose-dependent manner (36), while unsaturated fatty acids were unable to do so.

In conclusion, fatty acids are toxic to T-cells when administered in high concentrations and can induce proliferation and cytokine production when administered in non-toxic concentrations. The effects of fatty acids on T-cell function seem to be dependent not only on the saturation grade and length of fatty acids but also on the T-cell stimulus used.

MECHANISMS BY WHICH FATTY ACID EXERT THEIR EFFECTS How fatty acids exert their effects on different immune cells is incompletely understood, despite the fact that several possible mechanisms have been proposed. One possibility is that fatty acids can diffuse through the membrane of T-cells in a passive process, as some studies have shown that T-cells incorporate fatty acids in their membrane upon exposure $(38,39)$.

In addition to this passive mechanism, there are several active pathways possible, in general mediated by cellular receptors. Among the receptors involved in the recognition of free fatty acids, fatty acid transport proteins (FATPs) form a family of six transmembrane proteins, with distinct tissue expression patterns (40). FATPs are generally involved in the uptake of fatty acids, although there are no studies regarding their expression in T-cells. In addition to FATP, the fatty acid binding proteins (FABPs) are a family of homologous cytoplasmic proteins with high affinity for fatty acids. Even though FABPs are cytoplasmic proteins, it has been suggested that these FABPs play a role in uptake, transport, storage, and metabolism of fatty acids, with distinct patterns of tissue expression $(41,42)$. Interestingly, one of these receptors, the epidermal-FABP (FABP5) is also expressed on CD4 ${ }^{+}$T-cells (43).

Furthermore, a series of $\mathrm{G}$ protein-coupled receptors have been recently identified, which recognize fatty acids with different affinities and expression patterns. Five different receptors have been identified that recognize extracellular fatty acids with different lengths: free fatty acid receptor 1 (FFA1; GPR40) and GPR120 recognize long-chain fatty acids, GPR84 recognizes medium-chain fatty acids, while SCFA are recognized by FFA2 (GPR43) and FFA3 (GPR41) (44-46). The expression pattern of these receptors on T-cells has been only partly investigated. These studies indicated that FFA1 and FFA3 are not expressed on T-cells $(47,48)$, while the medium-chain fatty acid receptor, GPR84, is expressed by $\mathrm{CD}^{+}{ }^{+}$and $\mathrm{CD}^{+}$cells although less abundantly than by monocytes and neutrophils (49). Smith et al. recently showed that FFA2 is expressed on colonic regulatory T-cells (cTreg) (50).

In conclusion, several mechanisms could be involved in the modulation of T-cells function by fatty acids; a passive mechanism, in which the fatty acids diffuse through the membrane or active mechanisms, in which FATPs, FABPs, or other receptors could be involved. Their relative contribution to fatty acids uptake awaits further investigation.

\section{DOWNSTREAM EFFECTS OF FATTY ACIDS}

There are several studies regarding downstream effects of fatty acids. These studies focus mainly on the effects of OA, LA, or PA on resting human T-cells (36) or Jurkat cells (T-cell leukemia cell line) $(31,34,37,51,52)$. As previously mentioned fatty acids can influence T-cells in a dose-dependent manner, with low doses modulating proliferation and higher doses inducing apoptosis. Treatment of T-cells with fatty acids induces neutral lipid accumulation, such as triacylglycerol and cholesterol esters, and incorporation of the fatty acids in phospholipids $(31,34,37)$. The induction of neutral lipid accumulation is mediated by activation of insulin signaling pathways and glucose utilization, indicated by elevated expression of insulin receptor and GLUT4 and by increased glucose consumption and lactate production $(34,36)$.

It is believed that this pathway enables T-cells to evade the toxic effects of fatty acids at both low and high concentrations. However, when T-cells are exposed to too high concentrations, these mechanisms might not be sufficient to protect the cells from apoptosis and these results in the induction of intrinsic apoptotic pathways $(31,34,37)$.

Several apoptotic characteristics are induced by fatty acids in T-cells, such as mitochondrial depolarization $(31,34)$, caspase activation $(34,37)$, DNA fragmentation $(31,34)$, chromatin condensation (31), cytochrome $c$ (34), and phosphatidylserine externalization (31), indicating that T-cells treated with high-concentrations fatty acids die due to apoptosis. In addition, T-cells incubated with fatty acids also induce oxidative and nitrosative stress leading to apoptosis, indicated by higher levels of reactive oxygen species (ROS), reactive nitrogen species, and lower levels of catalase activity $(34,51,52)$.

How these mechanisms would affect proliferation and cytokine production of T-cells is unclear and awaits further investigation. Likewise, it is unclear whether these mechanisms are still utilized by T-cells that have been activated by their cognate antigen on antigen-presenting cells and which display an increased energy demand in order to proliferate, differentiate, and execute their effector functions.

In conclusion, free fatty acids induce proliferation of resting T-cells in low concentrations, while higher concentrations induce apoptosis. In Figure 1, we present possible mechanisms involved in the modulatory effects of fatty acids in T-cells.

\section{IN VIVO RELEVANCE}

As mentioned above, obese people express generally higher plasma levels of free fatty acids after fasting when compared to healthy controls. Likewise, the turnover rate of free fatty acids is higher after fasting $(14,15)$. Furthermore, some studies indicated T-cell numbers are decreased in obese persons (53-55) and T-cell proliferation and T-cell subset composition are altered compared to lean persons (54-57). The mechanisms underlying these differences between obese and lean individuals are unclear. However, some studies addressing the effect of dietary fatty acid content on the function of T-cells, both in rodent models (58-62) and in humans $(63,64)$ suggest that fatty acids can be modulators of T-cell function and phenotype also in vivo.

Rodent studies show that different high-fat diets can decrease PHA (58) and conA (60) induced proliferation of T-cells when compared to control diets. Furthermore, rodent models showed that diets rich in fatty acids can have an effect on IL-2 production and signaling, since IL-2 production (58) and the expression of IL-2 receptor $\alpha$-chain (CD25) (59) were increased when mice or rats are fed fatty acid rich diets. More recently, some studies investigated the effects of SCFAs on the immune system. SCFAs 


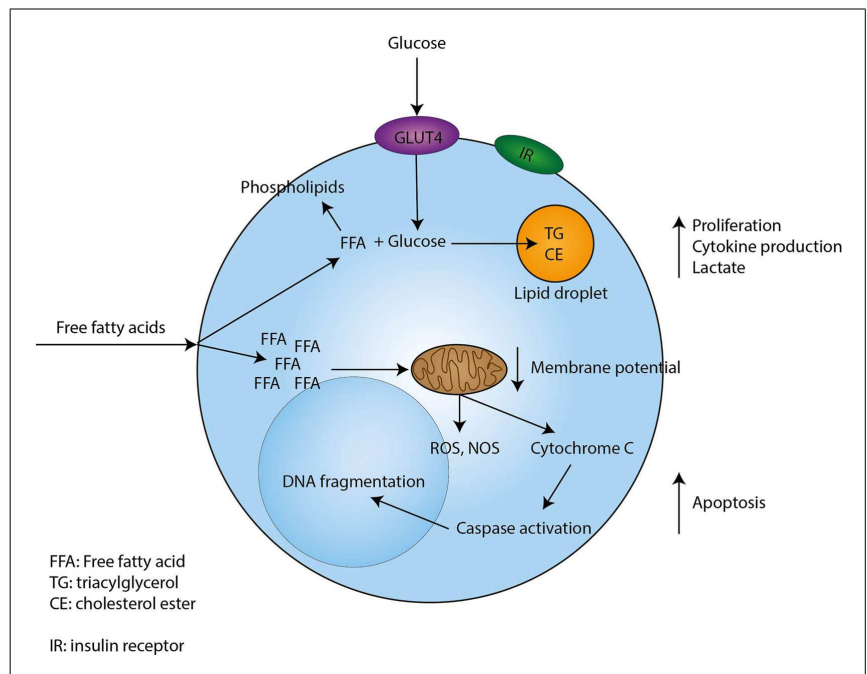

FIGURE 1 | Proposed mechanism through which free fatty acids exert their effects on T-cells. Free fatty acids enter T-cells through currently unknown mechanisms. Low concentrations of free fatty acids are incorporated in phospholipids, while uptake of glucose sustains the formation of triacylglycerol and cholesterol esters. In addition, low concentrations of free fatty acids induce proliferation, cytokine production, and lactate production by T-cells. However, when a T-cell encounters high concentrations of free fatty acids this will lead to depolarization of the mitochondrial membrane and the induction of intrinsic apoptotic pathways, which eventually lead to apoptosis

are metabolites of microbiota in the gut and are believed to play an important role in the balance between pro-inflammatory and anti-inflammatory effects in the gut. Indeed, recent studies show that adding SCFAs, especially butyrate and propionate, to the diet leads to induction of T-regulatory cells in the gut $(61,62)$. In line with this, butyrate was shown to ameliorate T-cell-dependent experimental colitis (61). In summary, these studies indicate that fatty acids can affect $\mathrm{T}$-cell proliferation, cytokine production, and skewing in vivo.

There are only two studies regarding the effect of dietary change of fatty acid content on the function of T-cells in humans $(63,64)$. A diet containing MUFAs did not affect conA stimulated T-cell proliferation (63), while another study using several diets with different fatty acids composition described a higher PHA and conA induced proliferation of T-cells compared to baseline for most diets investigated (64). A direct comparison of these studies is, however, difficult due to differences in diet composition.

Overall, the data suggest that fatty acids can influence both rodent and human T-cells in vivo. A firm conclusion is, however, difficult to formulate, as rodent studies show decrease in proliferation, while human studies either show unaffected proliferation or induction of proliferation. Furthermore, it remains uncertain whether the effects of saturated and unsaturated fatty acids are different.

\section{LIPID MEDIATORS}

Lipid mediators are produced through conserved biosynthetic pathways involving specific enzymes, which exert their function on lipid precursors that are released from membranes. There are several families of lipid mediators, which can be divided into proinflammatory lipid mediators and the more recently described specialized pro-resolving lipid mediators (SPM). Pro-inflammatory lipid mediators include prostaglandins and leukotrienes, while SPM include lipoxins, resolvins, maresins, and protectins (23).

\section{PRO-INFLAMMATORY LIPID MEDIATORS AND T-CELLS}

Prostaglandins and their influence on T-cells are widely studied and these studies have been reviewed elsewhere $(65,66)$. In short, PGE2 is the most studied prostaglandin and it has been shown to impair proliferative responses of T-cells (67-69). In addition, PGE2 can affect T-cell cytokine production, whereby Th17 associated cytokines, such as IL17, are upregulated (70-73). Moreover, PGE2 can change the Th1/Th2 balance by favoring Th2 skewing in vitro and in a mice model $(69,74)$. The effect of PGE2 on skewing of naïve T-cells toward Th17 cells is uncertain since there are contradicting studies showing either an induction of Th17 cells (75) or a reduction of Th17 cells (76), depending on the combination of cytokines used to induce Th17 differentiation. PGE2 can exert these effects on T-cells through E-prostanoid (EP) 2 receptor and EP4, which are present on T-cells $(72,73,75)$. So, prostaglandins can affect T-cell proliferation and T-cell skewing through the EP2 and EP4 receptors.

Another family of pro-inflammatory lipid mediators are the leukotrienes, but the effects of leukotrienes on T-cells are not completely known. A human study revealed that both Th1 and Th2 express cysteinyl leukotriene receptor 1 (CYSLTR1) mRNA, although expression of CYSLTR 1 was higher in Th2 cells compared to Th1 cells. In addition, activation of the CYSTLR1 with LTD4, LTC4, or LTE4 led to the induction of calcium signaling in Th2 cells, but a much weaker response in Th1 cells. LTD4 can also act as chemo attractant for Th2 cells (77). This indicates that Th2 cells are more susceptible than Th1 cells to respond to leukotrienes.

Different in vivo mice models have indicated that mice deficient in 5-lipoxygenase (5-LO), which is one of the key enzymes in leukotriene production, have less T-cells infiltrating the inflamed area (78-81), diminished numbers of $\mathrm{CD} 4^{+} \mathrm{CD} 25^{+}$regulatory T-cells, higher levels of IFN $\gamma$, and increased T-bet (Th1 lineage commitment) (80). In addition, LTB4 dose dependently downregulates the differentiation of naïve T-cells into Tregs, while it enhances the differentiation of Th17 cells, with more IL17 secretion and higher levels of ROR $\gamma t$ mRNA expression (82).

In summary, pro-inflammatory lipid mediators seem to stimulate T-cell migration (either directly or indirectly) and to favor skewing toward Th2 or Th17 instead of Th1 or Tregs.

\section{PRO-RESOLVING LIPID MEDIATORS AND T-CELLS}

Pro-resolving lipid mediators were recently described and have been shown to be involved in the resolution phase of inflammation. There are only a few studies investigating the effects of pro-resolving lipid mediators on T-cells; however, these studies indicate that these lipid mediators can influence T-cells.

Lipoxins, especially lipoxin A4 (LXA4) and lipoxin B4 (LXB4), have been shown to inhibit TNF $\alpha$ secretion from both PBMCs and peripheral T-cells stimulated with anti-CD3 Abs (83), and the effects observed with LXA4 were mediated by the LXA4 receptor (FPR2/ALX), expressed on T-cells $(83,84)$. FPR2/ALX expression 
is higher on activated $\mathrm{CD} 25^{+}$and memory $\mathrm{CD} 45 \mathrm{RO}^{+} \mathrm{CD} 4^{+}$ T-cells when compared to $\mathrm{CD} 25^{-}$and naïve $\mathrm{CD} 45 \mathrm{RA}^{+} \mathrm{CD} 4^{+}$ T-cells (84), indicating that activated T-cells can respond better to the agonist of this receptor.

Administration of resolvin D1 (RvD1) led to reduced infiltration of $\mathrm{CD}^{+}$and $\mathrm{CD} 8^{+} \mathrm{T}$-cells in the perivascular tissue of the eye of LPS induced uveitis in rats, resulting in the amelioration of the disease. This suggests that RvD1 prevents migration of T-cells into the eye, either directly or indirectly, thereby preventing disease in a rat model (85).

Moreover, protectin 1 (PD1) could reduce T-cell infiltration in zymosan A induced peritonitis (86) and into the lungs of OVAsensitized and challenged mice (87). Furthermore, in vitro studies show that PD1 inhibits cytokine secretion, such as TNF $\alpha$ and IFN $\gamma$ by T-cells and can induce apoptosis of T-cells (86). Therefore, PD1 could influence the inflammatory response by preventing the migration of T-cells and induction of apoptosis of T-cells.

In contrast to their pro-inflammatory counterparts, proresolving lipid mediators appear to inhibit cytokine production and migration of T-cells and to induce their apoptosis, thereby promoting resolution of inflammation.

\section{FUTURE RESEARCH PLANS}

In this review, we have summarized the current knowledge on the influence of fatty acids and lipid mediators on T-cells. These data indicate that fatty acids and their derivatives do affect the function and phenotype of T-cells and that the type and concentration of free fatty acids determines the outcome of this modulation and most likely the outcome of T-cell-dependent immune reactions. However, the presented data indicate that substantial further research is needed as there are still several remaining questions that need to be elucidated. These include a more detailed insight into the mechanisms involved in fatty acid uptake and usage by the cells, as well as into the possible in vivo impact of these changes.

Although some data exist on the effect of fatty acids on T-cell proliferation and cytokine production, these are inconsistent due to usage of different stimuli for T-cells. Future research should probably focus on more physiological stimuli, including antigenspecific stimulation using antigen-presenting cells. Moreover, the molecular events linking fatty acid uptake to modification of T-cell function and phenotype need to be identified, as they could constitute drug targets for future therapies of obesity-linked complications. Likewise, it is of interest whether stimulated cells use the same mechanisms as unstimulated cells to evade the toxic effects and the induction of proliferation and cytokines. Stimulated cells have a different energy demand than unstimulated cells, and therefore, could respond differently to fatty acids. This would be directly relevant for understanding modulation of ongoing immune responses by free fatty acids and consequently for development of efficient vaccination strategies or efficient drugs in T-cell-mediated diseases.

Additionally, in vivo studies systematically investigating the effect of various dietary fatty acids on T-cells would be needed as the current data are scarce and inconsistent. The latter is most likely due to a lack of standardization in the diets and the outcome measures used in the published studies. Also, current research is mainly focused on $\omega 3$ and $\omega 6$-rich diets, while relatively little is known about other fatty acids, which are also abundant in diet, such as OA, palmitic and palmitoleic acid, and others. Future research about the effect of these fatty acids is needed.

Current knowledge regarding the effects of lipid mediators on T-cells is mainly focused on pro-inflammatory lipid mediators. Therefore, research both in vitro and in vivo addressing the effects of pro-resolving lipid mediators on T-cell proliferation, differentiation, and function would be of interest. This would not only provide novel insights into the link between inflammation resolution and the adaptive immunity, which is a yet unexplored area of research, but could also lead to identification of new drug targets for modulation of T-cell responses.

\section{CONCLUDING REMARKS}

The Western world experiences an epidemic of obesity due to excess intake of food. Among the many nutrients acquired in excess, free fatty acids have an important impact on various bodily functions, as recent research has made clear. In this review, we have provided an overview of the current knowledge about the effects of fatty acids and their derivatives on T-cells. The summarized data indicate that the effect of fatty acids on T-cells is either stimulatory or lipotoxic, depending on the capacity of the T-cells to evade the toxic effects of the fatty acids. Both fatty acids and their oxidative derivatives can influence T-cell proliferation, skewing, and differentiation and this is usually dependent on the type of fatty acid. This suggests that the type of fatty acid in the diet, rather than its quantity, determine the outcome of an immune reaction in a certain individual. Future research will teach us whether and how fatty acids or lipid mediators can be used as drug targets in treating obesity-related or T-cell-driven diseases.

\section{REFERENCES}

1. Ouchi N, Parker JL, Lugus JJ, Walsh K. Adipokines in inflammation and metabolic disease. Nat Rev Immunol (2011) 11:85-97. doi:10.1038/nri2921

2. Hotamisligil GS. Inflammation and metabolic disorders. Nature (2006) 444:860-7. doi:10.1038/nature05485

3. Lago F, Dieguez C, Gomez-Reino J, Gualillo O. Adipokines as emerging mediators of immune response and inflammation. Nat Clin Pract Rheumatol (2007) 3:716-24. doi:10.1038/ncprheum0674

4. Yusuf E, Nelissen RG, Ioan-Facsinay A, Stojanovic-Susulic V, DeGroot J, van OG, et al. Association between weight or body mass index and hand osteoarthritis: a systematic review. Ann Rheum Dis (2010) 69:761-5. doi:10.1136/ard.2008. 106930

5. van der Helm-van Mil AH, van der Kooij SM, Allaart CF, Toes RE, Huizinga TW. A high body mass index has a protective effect on the amount of joint destruction in small joints in early rheumatoid arthritis. Ann Rheum Dis (2008) 67:769-74. doi:10.1136/ard.2007.078832

6. Paik J, Fierce Y, Treuting PM, Brabb T, Maggio-Price L. High-fat diet-induced obesity exacerbates inflammatory bowel disease in genetically susceptible Mdr1a-/- male mice. J Nutr (2013) 143:1240-7. doi:10.3945/jn.113.174615

7. Falagas ME, Kompoti M. Obesity and infection. Lancet Infect Dis (2006) 6:438-46. doi:10.1016/S1473-3099(06)70523-0

8. Sheridan PA, Paich HA, Handy J, Karlsson EA, Hudgens MG, Sammon AB, et al. Obesity is associated with impaired immune response to influenza vaccination in humans. Int J Obes (Lond) (2012) 36:1072-7. doi:10.1038/ijo.2011.208

9. Kershaw EE, Flier JS. Adipose tissue as an endocrine organ. J Clin Endocrinol Metab (2004) 89:2548-56. doi:10.1210/jc.2004-0395

10. Fain JN. Release of inflammatory mediators by human adipose tissue is enhanced in obesity and primarily by the nonfat cells: a review. Mediators Inflamm (2010) 2010:513948. doi:10.1155/2010/513948

11. Anderson EK, Gutierrez DA, Hasty AH. Adipose tissue recruitment of leukocytes. Curr Opin Lipidol (2010) 21:172-7. doi:10.1097/MOL.0b013e3283393867 
12. Fantuzzi G. Adipose tissue, adipokines, and inflammation. J Allergy Clin Immunol (2005) 115:911-9. doi:10.1016/j.jaci.2005.02.023

13. Boden G. Obesity and free fatty acids. Endocrinol Metab Clin North Am (2008) 37:635-6. doi:10.1016/j.ecl.2008.06.007

14. Bjorntorp P, Bergman H, Varnauskas E. Plasma free fatty acid turnover rate in obesity. Acta Med Scand (1969) 185:351-6. doi:10.1111/j.0954-6820.1969. tb07347.x

15. OPIE LH, WALFISH PG. Plasma free fatty acid concentrations in obesity. N Engl J Med (1963) 268:757-60. doi:10.1056/NEJM196304042681404

16. Perreault M, Roke K, Badawi A, Nielsen DE, Abdelmagid SA, El-Sohemy A, et al. Plasma levels of 14:0, 16:0, 16:1n-7, and 20:3n-6 are positively associated, but 18:0 and 18:2n-6 are inversely associated with markers of inflammation in young healthy adults. Lipids (2014) 49:255-63. doi:10.1007/s11745-013-3874-3

17. Wall R, Ross RP, Fitzgerald GF, Stanton C. Fatty acids from fish: the antiinflammatory potential of long-chain omega-3 fatty acids. Nutr Rev (2010) 68:280-9. doi:10.1111/j.1753-4887.2010.00287.x

18. Kris-Etherton PM, Harris WS, Appel LJ. Fish consumption, fish oil, omega3 fatty acids, and cardiovascular disease. Arterioscler Thromb Vasc Biol (2003) 23:e20-30. doi:10.1161/01.ATV.0000038493.65177.94

19. Vessby B. Dietary fat and insulin action in humans. Br J Nutr (2000) 83(Suppl 1):S91-6. doi:10.1017/S000711450000101X

20. Marshall JA, Bessesen DH. Dietary fat and the development of type 2 diabetes. Diabetes Care (2002) 25:620-2. doi:10.2337/diacare.25.3.620

21. Harrison LM, Balan KV, Babu US. Dietary fatty acids and immune response to food-borne bacterial infections. Nutrients (2013) 5:1801-22. doi:10.3390/ nu5051801

22. Anderson M, Fritsche KL. (n-3) Fatty acids and infectious disease resistance. J Nutr (2002) 132:3566-76.

23. Serhan CN. Resolution phase of inflammation: novel endogenous antiinflammatory and proresolving lipid mediators and pathways. Annu Rev Immunol (2007) 25:101-37. doi:10.1146/annurev.immunol.25.022106.141647

24. Serhan CN, Chiang N, Van Dyke TE. Resolving inflammation: dual antiinflammatory and pro-resolution lipid mediators. Nat Rev Immunol (2008) 8:349-61. doi:10.1038/nri2294

25. Vinolo MA, Rodrigues HG, Nachbar RT, Curi R. Regulation of inflammation by short chain fatty acids. Nutrients (2011) 3:858-76. doi:10.3390/nu3100858

26. Calder PC. Omega-3 fatty acids and inflammatory processes. Nutrients (2010) 2:355-74. doi:10.3390/nu2030355

27. Calder PC. The relationship between the fatty acid composition of immune cells and their function. Prostaglandins Leukot Essent Fatty Acids (2008) 79:101-8. doi:10.1016/j.plefa.2008.09.016

28. Akhtar KN. Polyunsaturated fatty acids in the modulation of T-cell signalling. Prostaglandins Leukot Essent Fatty Acids (2010) 82:179-87. doi:10.1016/j.plefa. 2010.02.023

29. Zurier RB, Rossetti RG, Seiler CM, Laposata M. Human peripheral blood T lymphocyte proliferation after activation of the $\mathrm{T}$ cell receptor: effects of unsaturated fatty acids. Prostaglandins Leukot Essent Fatty Acids (1999) 60:371-5. doi:10.1016/S0952-3278(99)80015-5

30. Lima TM, Kanunfre CC, Pompeia C, Verlengia R, Curi R. Ranking the toxicity of fatty acids on Jurkat and Raji cells by flow cytometric analysis. Toxicol In vitro (2002) 16:741-7. doi:10.1016/S0887-2333(02)00095-4

31. Cury-Boaventura MF, Pompeia C, Curi R. Comparative toxicity of oleic acid and linoleic acid on Jurkat cells. Clin Nutr (2004) 23:721-32. doi:10.1016/j. clnu.2003.12.004

32. Cury-Boaventura MF, Gorjao R, de Lima TM, Newsholme P, Curi R. Comparative toxicity of oleic and linoleic acid on human lymphocytes. Life Sci (2006) 78:1448-56. doi:10.1016/j.lfs.2005.07.038

33. Gorjao R, Cury-Boaventura MF, de Lima TM, Curi R. Regulation of human lymphocyte proliferation by fatty acids. Cell Biochem Funct (2007) 25:305-15. doi:10.1002/cbf. 1388

34. Takahashi HK, Cambiaghi TD, Luchessi AD, Hirabara SM, Vinolo MA, Newsholme P, et al. Activation of survival and apoptotic signaling pathways in lymphocytes exposed to palmitic acid. J Cell Physiol (2012) 227:339-50. doi:10.1002/jcp. 22740

35. Ioan-Facsinay A, Kwekkeboom JC, Westhoff S, Giera M, Rombouts Y, van HV, et al. Adipocyte-derived lipids modulate CD4(+) T-cell function. Eur J Immunol (2013) 43:1578-87. doi:10.1002/eji.201243096

36. Stentz FB, Kitabchi AE. Palmitic acid-induced activation of human Tlymphocytes and aortic endothelial cells with production of insulin receptors, reactive oxygen species, cytokines, and lipid peroxidation. Biochem Biophys Res Commun (2006) 346:721-6. doi:10.1016/j.bbrc.2006.05.159

37. Fernanda Cury-Boaventura M, Cristine KC, Gorjao R, Martins de LT, Curi R. Mechanisms involved in Jurkat cell death induced by oleic and linoleic acids. Clin Nutr (2006) 25:1004-14. doi:10.1016/j.clnu.2006.05.008

38. Szamel M, Rehermann B, Krebs B, Kurrle R, Resch K. Activation signals in human lymphocytes. Incorporation of polyunsaturated fatty acids into plasma membrane phospholipids regulates IL-2 synthesis via sustained activation of protein kinase C. J Immunol (1989) 143:2806-13.

39. Rossetti RG, Seiler CM, DeLuca P, Laposata M, Zurier RB. Oral administration of unsaturated fatty acids: effects on human peripheral blood $\mathrm{T}$ lymphocyte proliferation. J Leukoc Biol (1997) 62:438-43.

40. Stahl A, Gimeno RE, Tartaglia LA, Lodish HF. Fatty acid transport proteins: a current view of a growing family. Trends Endocrinol Metab (2001) 12:266-73. doi:10.1016/S1043-2760(01)00427-1

41. Storch J, Thumser AE. The fatty acid transport function of fatty acid-binding proteins. Biochim Biophys Acta (2000) 1486:28-44. doi:10.1016/S1388-1981(00) 00046-9

42. Haunerland NH, Spener F. Fatty acid-binding proteins - insights from genetic manipulations. Prog Lipid Res (2004) 43:328-49. doi:10.1016/j.plipres. 2004.05.001

43. Rolph MS, Young TR, Shum BO, Gorgun CZ, Schmitz-Peiffer C, Ramshaw IA, et al. Regulation of dendritic cell function and $\mathrm{T}$ cell priming by the fatty acidbinding protein AP2. J Immunol (2006) 177:7794-801. doi:10.4049/jimmunol. 177.11.7794

44. Vinolo MA, Hirabara SM, Curi R. G-protein-coupled receptors as fat sensors. Curr Opin Clin Nutr Metab Care (2012) 15:112-6. doi:10.1097/MCO. 0b013e32834f4598

45. Blad CC, Tang C, Offermanns S. G protein-coupled receptors for energy metabolites as new therapeutic targets. Nat Rev Drug Discov (2012) 11:603-19. doi: $10.1038 / \mathrm{nrd} 3777$

46. Yonezawa T, Kurata R, Yoshida K, Murayama MA, Cui X, Hasegawa A. Free fatty acids-sensing $G$ protein-coupled receptors in drug targeting and therapeutics. Curr Med Chem (2013) 20:3855-71. doi:10.2174/ 09298673113209990168

47. Briscoe CP, Tadayyon M, Andrews JL, Benson WG, Chambers JK, Eilert MM, et al. The orphan G protein-coupled receptor GPR40 is activated by medium and long chain fatty acids. J Biol Chem (2003) 278:11303-11. doi:10.1074/jbc. M211495200

48. Le PE, Loison C, Struyf S, Springael JY, Lannoy V, Decobecq ME, et al. Functional characterization of human receptors for short chain fatty acids and their role in polymorphonuclear cell activation. J Biol Chem (2003) 278:25481-9. doi:10.1074/jbc.M301403200

49. Wang J, Wu X, Simonavicius N, Tian H, Ling L. Medium-chain fatty acids as ligands for orphan G protein-coupled receptor GPR84. J Biol Chem (2006) 281:34457-64. doi:10.1074/jbc.M608019200

50. Smith PM, Howitt MR, Panikov N, Michaud M, Gallini CA, Bohlooly Y, et al The microbial metabolites, short-chain fatty acids, regulate colonic Treg cell homeostasis. Science (2013) 341:569-73. doi:10.1126/science.1241165

51. Cury-Boaventura MF, Curi R. Regulation of reactive oxygen species (ROS) production by C18 fatty acids in Jurkat and Raji cells. Clin Sci (Lond) (2005) 108:245-53. doi:10.1042/CS20040281

52. Azevedo-Martins AK, Curi R. Fatty acids decrease catalase activity in human leukaemia cell lines. Cell Biochem Funct (2008) 26:87-94. doi:10.1002/ cbf. 1404

53. Tanaka S, Isoda F, Ishihara Y, Kimura M, Yamakawa T. T lymphopaenia in relation to body mass index and TNF-alpha in human obesity: adequate weight reduction can be corrective. Clin Endocrinol (Oxf) (2001) 54:347-54. doi:10.1046/j.1365-2265.2001.1139cn2155.x

54. Tanaka S, Isoda F, Yamakawa T, Ishihara M, Sekihara H. T lymphopenia in genetically obese rats. Clin Immunol Immunopathol (1998) 86:219-25. doi:10.1006/clin.1997.4467

55. Boynton A, Neuhouser ML, Wener MH, Wood B, Sorensen B, Chen-Levy Z, et al. Associations between healthy eating patterns and immune function or inflammation in overweight or obese postmenopausal women. Am J Clin Nutr (2007) 86:1445-55.

56. Tanaka S, Inoue S, Isoda F, Waseda M, Ishihara M, Yamakawa $\mathrm{T}$, et al. Impaired immunity in obesity: suppressed but reversible lymphocyte responsiveness. Int J Obes Relat Metab Disord (1993) 17:631-6. 
57. Nieman DC, Henson DA, Nehlsen-Cannarella SL, Ekkens M, Utter AC, Butterworth DE, et al. Influence of obesity on immune function. J Am Diet Assoc (1999) 99:294-9. doi:10.1016/S0002-8223(99)00077-2

58. Mito N, Kitada C, Hosoda T, Sato K. Effect of diet-induced obesity on ovalbumin-specific immune response in a murine asthma model. Metabolism (2002) 51:1241-6. doi:10.1053/meta.2002.35196

59. Moussa M, Le BJ, Garcia J, Tkaczuk J, Ragab J, Dutot G, et al. In vivo effects of olive oil-based lipid emulsion on lymphocyte activation in rats. Clin Nutr (2000) 19:49-54. doi:10.1054/clnu.1999.0076

60. Yaqoob P, Newsholme EA, Calder PC. The effect of dietary lipid manipulation on rat lymphocyte subsets and proliferation. Immunology (1994) 82:603-10.

61. Furusawa Y, Obata Y, Fukuda S, Endo TA, Nakato G, Takahashi D, et al. Commensal microbe-derived butyrate induces the differentiation of colonic regulatory $\mathrm{T}$ cells. Nature (2013) 504:446-50. doi:10.1038/nature12721

62. Arpaia N, Campbell C, Fan X, Dikiy S, van der Veeken J, deRoos P, et al. Metabolites produced by commensal bacteria promote peripheral regulatory T-cell generation. Nature (2013) 504:451-5. doi:10.1038/nature12726

63. Yaqoob P, Knapper JA, Webb DH, Williams CM, Newsholme EA, Calder PC. Effect of olive oil on immune function in middle-aged men. Am J Clin Nutr (1998) 67:129-35.

64. Han SN, Lichtenstein AH, Ausman LM, Meydani SN. Novel soybean oils differing in fatty acid composition alter immune functions of moderately hypercholesterolemic older adults. J Nutr (2012) 142:2182-7. doi:10.3945/jn.112.164335

65. Sreeramkumar V, Fresno M, Cuesta N. Prostaglandin E2 and T cells: friends or foes? Immunol Cell Biol (2012) 90:579-86. doi:10.1038/icb.2011.75

66. Lone AM, Tasken K. Proinflammatory and immunoregulatory roles of eicosanoids in T cells. Front Immunol (2013) 4:130. doi:10.3389/fimmu.2013. 00130

67. Lee BP, Juvet SC, Zhang L. Prostaglandin E2 signaling through E prostanoid receptor 2 impairs proliferative response of double negative regulatory $\mathrm{T}$ cells. Int Immunopharmacol (2009) 9:534-9. doi:10.1016/j.intimp.2009.01.023

68. English K, Tonlorenzi R, Cossu G, Wood KJ. Mesoangioblasts suppress T cell proliferation through IDO and PGE-2-dependent pathways. Stem Cells Dev (2013) 22:512-23. doi:10.1089/scd.2012.0386

69. Bao YS, Zhang P, Xie RJ, Wang M, Wang ZY, Zhou Z, et al. The regulation of CD4+ $\mathrm{T}$ cell immune responses toward Th2 cell development by prostaglandin E2. Int Immunopharmacol (2011) 11:1599-605. doi:10.1016/j. intimp.2011.05.021

70. Adamik J, Henkel M, Ray A, Auron PE, Duerr R, Barrie A. The IL17A and IL17F loci have divergent histone modifications and are differentially regulated by prostaglandin E2 in Th17 cells. Cytokine (2013) 64:404-12. doi:10.1016/j.cyto. 2013.05.010

71. Barrie A, Khare A, Henkel M, Zhang Y, Barmada MM, Duerr R, et al. Prostaglandin E2 and IL-23 plus IL-1beta differentially regulate the Th1/Th17 immune response of human CD161(+) CD4(+) memory T cells. Clin Transl Sci (2011) 4:268-73. doi:10.1111/j.1752-8062.2011.00300.x

72. Napolitani G, Acosta-Rodriguez EV, Lanzavecchia A, Sallusto F. Prostaglandin E2 enhances Th17 responses via modulation of IL-17 and IFN-gamma production by memory CD4+ T cells. Eur J Immunol (2009) 39:1301-12. doi:10.1002/ eji.200838969

73. Yao C, Sakata D, Esaki Y, Li Y, Matsuoka T, Kuroiwa K, et al. Prostaglandin E2EP4 signaling promotes immune inflammation through Th1 cell differentiation and Th17 cell expansion. Nat Med (2009) 15:633-40. doi:10.1038/nm.1968

74. Machado ER, Carlos D, Lourenco EV, Souza GE, Sorgi CA, Silva EV, et al. Cyclooxygenase-derived mediators regulate the immunological control of Strongyloides venezuelensis infection. FEMS Immunol Med Microbiol (2010) 59:18-32. doi:10.1111/j.1574-695X.2010.00656.x

75. Boniface K, Bak-Jensen KS, Li Y, Blumenschein WM, McGeachy MJ, McClanahan TK, et al. Prostaglandin E2 regulates Th17 cell differentiation and function through cyclic AMP and EP2/EP4 receptor signaling. J Exp Med (2009) 206:535-48. doi:10.1084/jem.20082293

76. Valdez PA, Vithayathil PJ, Janelsins BM, Shaffer AL, Williamson PR, Datta SK. Prostaglandin E2 suppresses antifungal immunity by inhibiting interferon regulatory factor 4 function and interleukin-17 expression in T cells. Immunity (2012) 36:668-79. doi:10.1016/j.immuni.2012.02.013

77. Parmentier CN, Fuerst E, McDonald J, Bowen H, Lee TH, Pease JE, et al. Human $\mathrm{T}(\mathrm{H}) 2$ cells respond to cysteinyl leukotrienes through selective expression of cysteinyl leukotriene receptor 1. J Allergy Clin Immunol (2012) 129:1136-42. doi:10.1016/j.jaci.2012.01.057

78. Secatto A, Rodrigues LC, Serezani CH, Ramos SG, Dias-Baruffi M, Faccioli LH, et al. 5-Lipoxygenase deficiency impairs innate and adaptive immune responses during fungal infection. PLoS One (2012) 7:e31701. doi:10.1371/journal.pone. 0031701

79. Mothe-Satney I, Filloux C, Amghar H, Pons C, Bourlier V, Galitzky J, et al. Adipocytes secrete leukotrienes: contribution to obesity-associated inflammation and insulin resistance in mice. Diabetes (2012) 61:2311-9. doi:10.2337/ db11- 1455

80. Tristao FS, Rocha FA, Moreira AP, Cunha FQ, Rossi MA, Silva JS. 5-Lipoxygenase activity increases susceptibility to experimental Paracoccidioides brasiliensis infection. Infect Immun (2013) 81:1256-66. doi:10.1128/IAI.01209-12

81. Narushima S, DiMeo D, Tian J, Zhang J, Liu D, Berg DJ. 5-Lipoxygenase-derived lipid mediators are not required for the development of NSAID-induced inflammatory bowel disease in IL-10-/- mice. Am J Physiol Gastrointest Liver Physiol (2008) 294:G477-88. doi:10.1152/ajpgi.00229.2007

82. Chen H, Qin J, Wei P, Zhang J, Li Q, Fu L, et al. Effects of leukotriene B4 and prostaglandin E2 on the differentiation of murine Foxp3+ T regulatory cells and Th17 cells. Prostaglandins Leukot Essent Fatty Acids (2009) 80:195-200. doi:10.1016/j.plefa.2009.01.006

83. Ariel A, Chiang N, Arita M, Petasis NA, Serhan CN. Aspirin-triggered lipoxin A4 and B4 analogs block extracellular signal-regulated kinase-dependent TNFalpha secretion from human T cells. J Immunol (2003) 170:6266-72. doi:10. 4049/jimmunol.170.12.6266

84. Spurr L, Nadkarni S, Pederzoli-Ribeil M, Goulding NJ, Perretti M, D'Acquisto F. Comparative analysis of Annexin A1-formyl peptide receptor 2/ALX expression in human leukocyte subsets. Int Immunopharmacol (2011) 11:55-66. doi:10.1016/j.intimp.2010.10.006

85. Settimio R, Clara DF, Franca F, Francesca S, Michele D. Resolvin D1 reduces the immunoinflammatory response of the rat eye following uveitis. Mediators Inflamm (2012) 2012:318621. doi:10.1155/2012/318621

86. Ariel A, Li PL, Wang W, Tang WX, Fredman G, Hong S, et al. The docosatriene protectin D1 is produced by $\mathrm{TH} 2$ skewing and promotes human $\mathrm{T}$ cell apoptosis via lipid raft clustering. J Biol Chem (2005) 280:43079-86. doi:10.1074/jbc. M509796200

87. Levy BD, Kohli P, Gotlinger K, Haworth O, Hong S, Kazani S, et al. Protectin D1 is generated in asthma and dampens airway inflammation and hyperresponsiveness. J Immunol (2007) 178:496-502. doi:10.4049/jimmunol.178.1.496

Conflict of Interest Statement: The authors declare that the research was conducted in the absence of any commercial or financial relationships that could be construed as a potential conflict of interest.

Received: 14 August 2014; paper pending published: 09 September 2014; accepted: 22 September 2014; published online: 13 October 2014.

Citation: de Jong AJ, Kloppenburg M, Toes REM and Ioan-Facsinay A (2014) Fatty acids, lipid mediators, and T-cell function. Front. Immunol. 5:483. doi: 10.3389/fimmu.2014.00483

This article was submitted to Inflammation, a section of the journal Frontiers in Immunology.

Copyright (c) 2014 de Jong, Kloppenburg, Toes and Ioan-Facsinay. This is an openaccess article distributed under the terms of the Creative Commons Attribution License (CC BY). The use, distribution or reproduction in other forums is permitted, provided the original author(s) or licensor are credited and that the original publication in this journal is cited, in accordance with accepted academic practice. No use, distribution or reproduction is permitted which does not comply with these terms. 